merase chain reaction for the detection of DNA damage. Mar. Environ. Res. 46:331-335.

2.Atienzar, F., M. Conradi, A. Evenden, A. Jha and M. Depledge. 1999. Qualitative assessment of genotoxicity using random amplified polymorphic DNA: comparison of genomic template stability with key fitness parameters in Daphnia magna exposed to benzo(a)pyrene. Environ. Toxicol. Chem. 18:2275-2282.

3.Atienzar, F., B. Cordi, M. Donkin, A. Evenden, A. Jha and M. Depledge. Comparison of ultraviolet induced genotoxicity detected by RAPD with chlorophyll fluorescence and growth in a marine macroalgae, Palmaria palmata. Aquat. Toxicol. (In press).

4.Ayliffe, M.A., G.J. Lawrence, J.G. Ellis and A.J. Pryor. 1994. Heteroduplex molecules formed between allelic sequences cause nonparental RAPD bands. Nucleic Acids Res. 22:1632-1636.

5.Bentley, S. and B.J. Bassam. 1996. A robust DNA amplification fingerprinting system applied to analysis of genetic variation within Fusarium oxysporum f.sp. cubense. J. Phytopathol. 144:207-213.

6.Caetano-Anollés, G. 1998. DAF optimization using Taguchi methods and the effect of thermal cycling parameters on DNA amplification. BioTechniques 25:472-480.

7.Caetano-Anollés, G., B.J. Bassam and P.M. Gresshoff. 1991. DNA amplification fingerprinting using very short arbitrary oligonucleotide primers. Biotechnology 9:553-557.

8.Ellsworth, D.L., K.D. Rittenhouse and R.L Honeycutt. 1993. Artifactual variation in randomly amplified polymorphic DNA banding patterns. BioTechniques 14:214-217.

9.Mullis, K.B. 1991. The Polymerase Chain Reaction in an anemic mode: how to avoid cold oligodeoxyribonuclear fusion. PCR Methods and Applications 1:1-4.

10.Ruano, G., W. Fenton and K.K. Kidd. 1989. Biphasic amplification of very dilute DNA samples via booster PCR. Nucleic Acids Res. 17:5407.

11.Welsh, J., D. Ralph and M. McClelland. 1995. DNA and RNA fingerpinting using arbitrarily primed PCR, p. 249-276. In M.A. Innis, D.H. Gelfand and J.J. Sninsky. (Eds.), PCR Strategies. Academic Press, San Diego.

12.Williams, J.G.K., A.R. Kubelic, K.J. Livak, J.A. Rafalski and S.V. Tingey. 1990. DNA polymorphisms amplified by arbitrary primers are useful as genetic-markers. Nucleic Acids Res. 18:6531-6535.

Financial support from the European Commission (Marie Curie Grant No. ERB4001-GT-97-0136) is gratefully acknowledged. Address correspondence to Franck Atienzar, Department of Biological Sciences and Plymouth Environmental ResearchCenter (PERC), University of Plymouth, Drake Circus, Plymouth, PL48AA, England, UK. Internet:fatienzar@plymouth.ac.uk

Received 28 June 1999; accepted 19 October 1999.
F. Atienzar, A. Evenden, A. Jha, D. Savva ${ }^{1}$ and M. Depledge University of Plymouth Plymouth, England, UK ${ }^{1}$ The University of Reading Reading, England, UK

\section{Improved Analysis of Promoter Activity in Biolistically Transformed Plant Cells}

BioTechniques 28:54-58 (January 2000)

A common way to analyze gene expression involves the use of transgenic plants. Transient assays that use particle bombardment (9) are a powerful alternative to rapidly evaluate gene expression in intact plant tissues. If the particular system in use has been validated by another approach, the results provide a meaningful indicator of the expression of stable genes in plants. Even for verified transient assay systems, a critical problem often associated with particle bombardment is that of high data dispersion. On the other hand, the choice of the assay (histochemical or fluorometric) used to quantify promoter activity in gus-based constructs could lead to misinterpretation of the data because of the different sensitivities for GUS detection among assays. The aim of this work was to find a way to decrease data dispersion and to evaluate the consistency of the two assays of GUS activity used to determine the promoter activity in transient assays.

To address the data dispersion problem, we used the $C l$ and $B$-Peru genes from maize as internal controls. These genes code for transcriptional factors that activate the anthocyanin biosynthetic pathway $(1,10)$. The level of anthocyanin was used as a visual marker to select only samples with high levels of transformed cells. A major factor causing data dispersion is the unequal dispersion of particles among different bombardments and among distinct samples in the same bombardment. Internal controls coding for other reporter enzymes under the control of constitutive promoters are generally used to normalize the data dispersion. However, when using internal controls, it is desirable to identify efficiently transfected samples before undertaking the laborious process of protein extraction and quantification of the promoter activities of the test and control constructs.

In these experiments, we evaluated the co-bombardment of the test DNA construct together with constructs containing the $C l$ and $B$-Peru genes $(1,10)$. After bombarding tissues from maize, wheat, petunia, pea and white clover with these two genes under the control of the cauliflower mosaic virus (CaMV) $35 \mathrm{~S}$ promoter, the transformed cells become colored as a result of anthocyanin accumulation and can be seen with the naked eye $(1,2,7,10,11,13)$.

The constructs p35SC1, pB-Peru (anthocyanin accumulation) and pAH18 (luciferase production) were used as internal controls, and p699 was used as a test construct to direct GUS production. GUS activity is expressed as pmol 4-methylumbelliferone (4-MU) $\mathrm{min}^{-1}$ $\mathrm{mg}^{-1}$. Both $\mathrm{p} 35 \mathrm{SC} 1$ and $\mathrm{pB}-$ Peru contain the CaMV 35S promoter and the first intron of maize Adh1, fused to the $C 1$ and $B$-Peru gene coding regions, respectively (kindly provided by $\mathrm{S}$. Wessler). The pAH18 contains the maize ubiquitin promoter and its first intron fused to the firefly luciferase coding region (5). The p699 is a deletion of the Hrgp promoter obtained from an AC1503 maize genomic clone (EMBL Accession No. AJ131535) with the $3^{\prime}$ end at +16 and the $5^{\prime}$ end at -699 (numbering relative to the ATG start codon), fused in frame to a $g u s A / 3^{\prime}$ NOS fragment (12). The maize Hrgp gene codes for a hydroxyproline-rich glycoprotein that is present in cell walls (15), and the promoter shows high activity in young shoots and immature embryos (12).

When intact maize tissues with irregular shapes were bombarded, there was a high level of data dispersion, even among samples in the same petri dish. In a representative experiment (Figure 1), young seedlings were bom- 
barded with $\mathrm{pB}-\mathrm{Peru}$ and $\mathrm{p} 35 \mathrm{SC} 1$, together with p699 and pAH18 constructs. The number of bronze spots representing the anthocyanin genes expression in each seedling was scored under a stereomicroscope $24 \mathrm{~h}$ after bombardment. GUS activity in each seedling was assayed fluorometrically and varied from zero to approximately $300 \mathrm{pmol}$ of $4-\mathrm{MU} \mathrm{min}^{-1} \mathrm{mg}^{-1}$. There was a positive correlation between the GUS activity of each seedling and the number of bronze spots (Figure 1). The mean GUS $( \pm$ SEM) of all the samples shown in Figure 1 was $85 \pm 22$ pmol 4 $\mathrm{MU} / \mathrm{min} / \mathrm{mg}$ protein: the SEM corresponded to $26 \%$ of the mean.

After eliminating samples with less than 150 bronze spots that produce low GUS activity, the mean GUS activity increased to $124 \pm 23$, with the SEM rep-

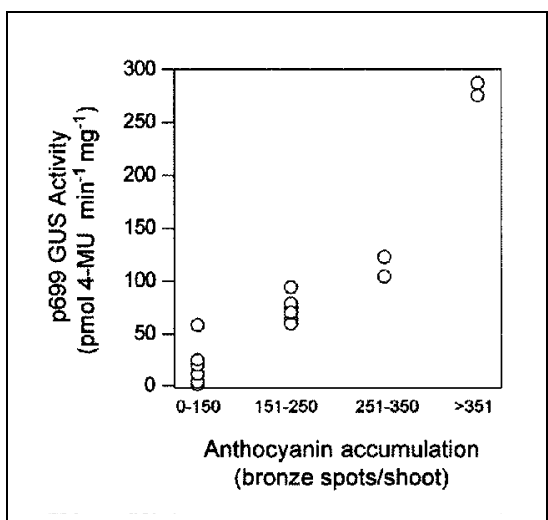

Figure 1. Correlation between anthocyanin accumulation and GUS activity in young maize seedlings. Maize seedlings were bombarded with p699, pAH18 and pB-Peru and p35SC1 plasmids. Particle preparation and DNA coating were carried out (12) using $8 \mu \mathrm{L}$ of DNA-GUS construct $(0.5 \mu \mathrm{g} / \mu \mathrm{L}$ in TE buffer, $\mathrm{pH} 8.0)$ and $15 \mu \mathrm{L}$ of a control mixture containing $25 \mathrm{ng}$ of pB-Peru, $25 \mathrm{ng}$ of $\mathrm{p} 35 \mathrm{SC} 1$ and $1 \mu \mathrm{g}$ of pAH18 in each preparation. Bombardment was done with a PDS1000/He device (Bio-Rad Laboratories, Hercules, CA, USA) using settings already described (12). Nine young seedlings (three days after germination) of the maize inbred line W64A were distributed in petri dishes containing MS media (MS salts and vitamins, $30 \mathrm{~g}$ sucrose/L, $2.4 \mathrm{~g}$ Gelrite/L, $\mathrm{pH}$ 5.8). The number of bronze spots in the shoot of each seedling was scored $24 \mathrm{~h}$ after bombardment. A protein extract from each shoot was subsequently obtained by homogenization in 150 $\mu \mathrm{L}$ of luciferase lysis buffer (luciferase assay system, Promega, Madison, WI, USA). The GUS activity, directed by p699, was quantified fluorometrically with a TK 1000 fluorometer (Amersham Pharmacia Biotech, Piscataway, NJ, USA). Points represent the GUS activity (pmol 4-MU $\mathrm{min}^{-1} \mathrm{mg}^{-1}$ ) versus the number of bronze spots scored in each seedling. resenting $18 \%$ of the mean. To further reduce data variability, the luciferase activity directed by pAH18 in each seedling also was assayed. To normalize the activity driven by the 1699 construct in each seeding, the GUS activity (pmol 4-MU $\mathrm{min}^{-1} \mathrm{mg}^{-1}$ ) was divided by the luciferase activity ( $\mathrm{mV}$ per 10$)$. Using this second internal control, the SEM as a percentage of the mean was further reduced from $18 \%$ to $10 \%$. This approach gave also excellent results when immature embryos, endosperms, young leaves and BMS suspension cell cultures were transformed by particle bombardment (data not shown).

Another possible problem associated with transient expression assays that use particle bombardment is the method for quantifying GUS activity. The quantification of promoter activity by histochemical detection of GUS ac-

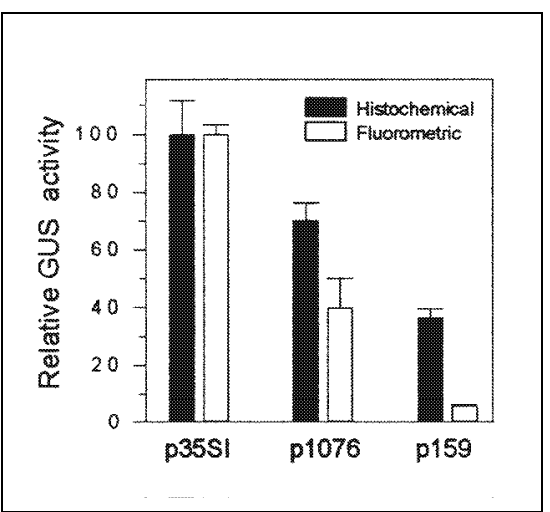

Figure 2. Comparison of histochemical and fluorometric assays for the quantification of GUS activity. Maize embryos (14 days after pollination) were flattened onto MS media (9 per dish) and bombarded with p35SI, p1076 and p159 in co-transformation with pAH18, as described in Figure 1. The histochemical assay of GUS activity using X-Gluc as substrate was performed as described (12) and the blue spots in each embryo were counted under a stereomicroscope. Fluorometric measurements of GUS activity were performed as before by using the protein extract prepared from the 9 embryos of each dish. Luciferase activity was quantified in a $1250 \mathrm{Lu}-$ minometer (BioOrbit, Turku, Finland) by mixing $20 \mu \mathrm{L}$ of protein extract with $100 \mu \mathrm{L}$ of reaction buffer (luciferase assay system; Promega) and taking the measurments after $10 \mathrm{~s}$. To normalize promoter activity, the GUS value detected in each sample was divided by the luciferase value obtained in the same sample. Black bars indicate the average number of blue spots seen following the histochemical assay $(\mathrm{n}=58)$ and the white bars represent the mean GUS/luciferase activities based on the fluorometric assay $(n=4)$. In both cases, the activity of p35SI was considered as $100 \%$. The error bars represent the SEM. 
tivity, followed by counting the number of blue spots produced, is widely used because of its simplicity $(4,6,14)$. However, theoretical considerations indicate that the fluorometric assay of GUS activity may be better for this purpose. The number of blue spots in immature embryos that were bombarded with constructs containing GUS fused to three Hrgp promoter deletions was found to be similar, although the intensity of the spots differed (data not shown). These variations probably reflect distinct levels of GUS activitydriven promoters, which differed in strength. In this case, counting the spots would erroneously estimate the activity of promoters that varied in strength.

To test this hypothesis, immature embryos were bombarded with p35SI and p1076 and p159 constructs, and two methods for detecting GUS activities were compared. The p35SI construct contains a $450 \mathrm{bp} 35 \mathrm{~S}$ promoter fused to the first intron of the $A d h 1-S$ gene (3), to a gusA coding region and to nopaline synthase terminator (3'NOS) from pBi121 (8). The constructs p1076 and p159 are deletions of the HRGP promoter fused to the gusA gene, with the $5^{\prime}$ end at -1076 and -159 , respectively.

The two assays detected that GUS activity varied with the promoter, although there were discrepancies in the activity of a given promoter (Figure 2). Thus, the activity of p1076 was 70\% that of p35SI when the blue spot counting method was used, but only $40 \%$ when the fluorometric assay was used. The 159 construct showed even greater discrepancies $(40 \%$ of the p35SI construct value in the blue spot counting method and only $6 \%$ in the fluorometric assay). An essential assumption of the blue spot counting method is that the stronger the promoter, the higher the probability that one transformed cell will produce a sufficient amount of re- action product to give a detectable blue spot. However, our results indicate that with this method, there is a clear overestimation of the activity of weak promoters. The GUS fluorometric assay was more accurate in detecting differences in the activities directed by distinct constructions and provided a more faithful determination of promoter activity. This is probably because the histochemical spot-counting method does not allow for the distinction between light and dark blue spots. Thus, once a cell (or a group of cells) reaches the threshold for color detection by the naked eye, it will be considered a unit in the same manner as dark spots with higher GUS activity.

In summary, our approach using two internal control systems greatly decreases data variability. It also decreases the amount of time and money necessary to prepare protein extracts and assay GUS and luciferase activities from non-transformed and poorly 
transformed samples. This system will probably be useful in other species that respond to transformation with the $C 1$ and B-Peru genes. Our results also show that the histochemical spot-counting method for the quantification of promoter-driven GUS activity may understimate the activity of strong promoters. Irrespective of the species being studied, the fluorometric assay is preferred for this reason when quantifying promoter-driven GUS activity.

\section{REFERENCES}

1.Bowen, B. 1992. Anthocyanin genes as visual markers in transformed maize tissues, pp. 163-177. In S.R. Gallagher (Ed.), Gus Protocols: Using the GUS Gene as a Reporter of Gene Expression. Academic Press, San Diego, CA.

2.Bowen, B., J. Bennetzen, C. Nagai, S. Sun and B. Roth. 1991. Targets for trans-activation by maize $\mathrm{R}$ and $\mathrm{C}$ proteins conserved in other monocots. Abstract 1093, 3rd International Congress of Plant Molecular Biology, Tucson, AZ, USA.

3.Callis, J., M. Fromm and V. Walbot. 1987. Introns increase gene expression in cultured maize cells. Genes Dev. 1:1183-1200.

4.Chowdhury, M.K.U., G.K.A. Parveez and N.M. Saleh. 1997. Evaluation of five promoters for use in transformation of oil palm (Elaeis guineensis Jacq.). Plant Cell Rep. 16:277-281.

5.Cornejo, M.J., D. Luth, K.M. Blankenship, O.D. Anderson and A.E. Blechl. 1993. Activity of a maize ubiquitin promoter in transgenic rice. Plant Mol. Biol. 23:567-581.

6.Eady, C.C., C.E. Lister, Y. Suo and D. Schaper. 1996. Transient expression of uidA constructs in in vitro onion (Allium cepa L.) cultures following particle bombardment and Agrobacterium-mediated DNA delivery. Plant Cell Rep. 15:958-962.

7.Iglesias, V.A., A. Gisel, R. Bilang, N. Leduc, I. Potrykus and C. Sautter. 1994. Transient expression of visible marker genes in meristem cells of wheat embryos after ballistic micro-targeting. Planta 192:84-91.

8.Jefferson, R.A. 1987. Assaying chimeric genes in plants: the GUS gene fusion system. Plant Mol. Biol. Rep. 5:387-405.

9.Klein, T.M., L.T. Gradziel, M.E. Fromm and J.C. Sanford. 1988. Factors influencing gene delivery into Zea mays cells by high-velocity microprojectiles. Biotechnology 6:559563.

10.Ludwig, S.R., B. Bowen, L. Beach and S.R. Wessler. 1990. A regulatory gene as a novel visible marker for maize transformation. Science 247:449-450.

11.Majnik, J., G.J. Tanner, R.G. Joseph, P.J. Larkin, J.J. Weinman, M.A. Djordjevic and B.G. Rolfe. 1998. Transient expression of maize anthocyanin regulatory genes influences anthocyanin production in white clover and peas. Aust. J. Plant Physiol. 25:335-343.
12.Menossi, M., J.A. Martènez-Izquierdo and P. Puigdomènech. 1997. Tissue specific activity and hormone control of the promoter of the gene coding for a maize hydroxyprolinerich glycoprotein. Plant Sci. 125:189-200.

13.Quatrochio, F., J.F. Wing, H.T.C. Leppen, J.N.M. Mol and R.E. Koes. 1993. Regulatory genes controlling anthocyanin pigmentation are functionally conserved among plant species and have distinct sets of target genes. Plant Cell 5:1497-1512.

14.Souza Filho, G.A., M.J. da Silva, A.L. Vettore, J.A. Yunes, A. Leite, P. Arruda and L.M.M. Ottoboni. 1999. Identification of a DNA-binding factor that recognizes an $(\alpha$-coixin promoter and interacts with a Coix Opaque-2 like protein. Plant Mol. Biol. 39:95104.

15.Stiefel, V., L. Ruiz-Avila, R. Raz, M.P. Valles, J. Gomez, M. Pages, J.A. MartínezIzquierdo, M.D. Ludevid et al. 1990. Expression of a maize cell wall hydroxyprolinerich glycoprotein gene in early leaf and root vascular differentiation. Plant Cell 2:785-793.

The authors thank Dr. P. Fontanet for invaluable help with maize plant materials, Dr. R. Raz for providing the AC1503 maize Hrgp genomic clone and Drs. S. Wessler and $V$. Walbot for providing plasmid constructs. This research was supported by the Dirección General de Política Científica (Grant No. PB93-0043) and Plan Nacional de Investigación Científica y Técnica (Grant No. BIO 94-0734). M.M. was the recipient of a predoctoral fellowship from CNPq/RHAE, Brazil. Address correspondence to Dr. Marcelo Menossi, Centro de Biologia Molecular e Engenharia Genética, Departamento de Genética e Evolução, C.P. 6109, Universidade Estadual de Campinas, CEP 13083-970, Campinas, SP, Brazil. Intenet:menossi@unicamp.br

Received 2 March 1999; accepted 4 October 1999.

\section{Marcelo Menossi ${ }^{1,2}$, Pere Puigdomènech ${ }^{1}$ and José $\mathrm{A}$. Martínez-Izquierdo ${ }^{1}$ ${ }^{1}$ Centro de Investigación y Desarrollo, CSIC Barcelona, Spain ${ }^{2}$ Universidade Estadual de Campinas Campinas, SP, Brazil}

